\title{
SUPPURATIVE ARTHRITIS OF INFANCY
}

\section{Some Observations upon Prognosis and Management}

\author{
G. C. Lloyd-Roberts, London, England \\ From the Victoria Hospital for Children, Tite Street (St George's Hospital Group), \\ and the Hospital for Sick Children, Great Ormond Street, London
}

Some infants with pyogenic arthritis develop alarming radiographic signs which may give a false impression of the extent to which the joint has been damaged by the infection. The prognosis may, in fact, be relatively good and a favourable outcome predicted with confidence in some of these children.

The surgeon who relies upon radiological signs alone and ignores clinical features may in time be embarrassed by a surprisingly good result when he has warned the parents that a serious disability will follow. He may also be misguided enough to operate unnecessarily or, by not operating, he may lose the opportunity to alleviate the effects of the disease. Such mistakes can occur because the decalcification caused by the infection extends beyond the limits of the epiphysis into the metaphysis, where secondary changes may further suggest irreparable damage not only to the epiphysis and metaphysis but also to the intervening epiphysial plate. The final shape of the articulating surfaces is, however, dependent not upon the degree of decalcification of the ossific nucleus or the nearby metaphysis (these changes are reversible), but upon the damage caused to the epiphysial cartilage and plate which cannot be seen in an early radiograph. It was, indeed, demonstrated by Haas (1919) that it is possible to scrape out the entire epiphysial ossific nucleus without affecting the ultimate shape of the bone.

The thirteen patients reported here to illustrate certain features of infantile pyogenic arthritis affecting the knee and hip were all seen within the last three years, so it is not very rare. Several of the cases arose in the practice of colleagues who, knowing my interest, have generously allowed me to treat their patients or to see them, and have made their records available to me. Although it seems likely that prompt treatment by antibiotics aids the survival of the joint it should be noted that an illustration very similar to Figure 24 may be found in Jones and Lovett's text-book of orthopaedics (1923). This patient and three others with hip joint involvement reported by Banks, Krigsten and Compere (1940) illustrate the surprising degree of recovery that can occur without antibiotic or chemotherapeutic drugs.

\section{PYOGENIC ARTHRITIS OF THE KNEE}

The syndrome is well illustrated by an account of the first patient in the series in whom an error in management was so shaming that a careful reappraisal established the main clinical and radiological features upon which the diagnosis has been made subsequently.

\section{CASE REPORT}

Case 1-A girl aged twenty-one months was admitted under Dr C. W. Kesson with left genu valgum (Figs. 1 and 2). At the age of five days septicaemia from umbilical sepsis had been diagnosed and treated with antibiotics. A month later both knees were found to be swollen, thick pus was aspirated and staphylococcus aureus was grown. The organism was insensitive to penicillin but sensitive to erythromycin, which was prescribed immediately and continued for six weeks. Traction was maintained for a further two weeks, and she was discharged to out-patient supervision. 


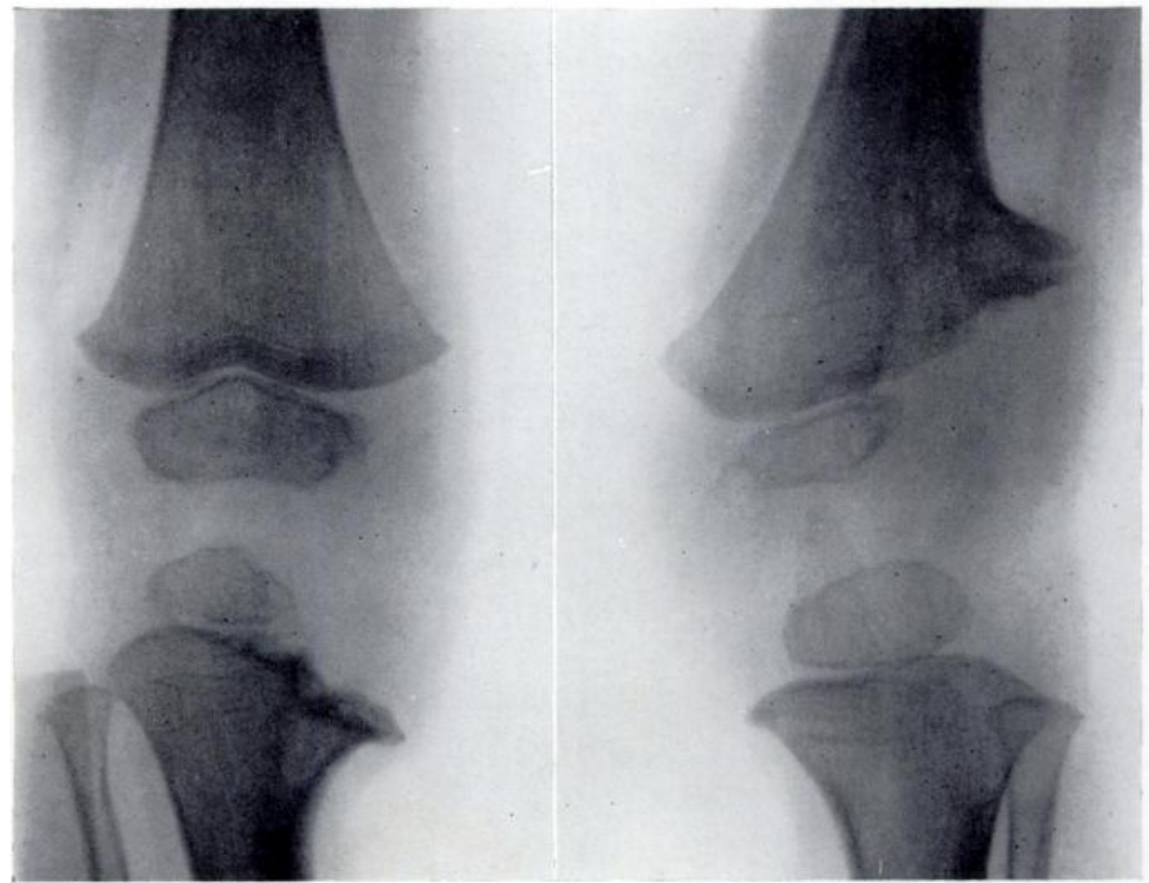

Fig. 1

Case 1-The appearances of both knees at the age of twenty-one months. Note the apparent loss of half the epiphyses on both sides, the sloping epiphysial plate and the metaphysial spurs.

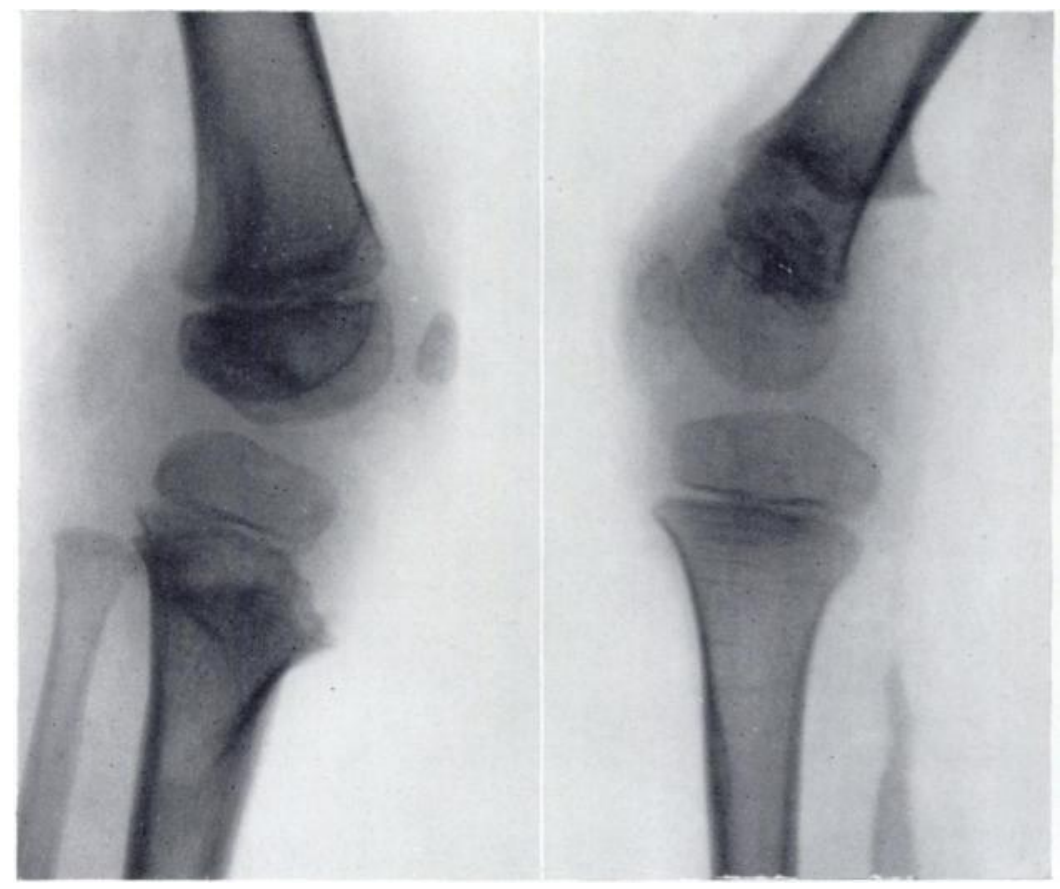

FiG. 2

Case 1-Showing the typical metaphysial spurs in the lateral view. The head of the left fibula has been removed. 
When she was first admitted there was a 30 degrees genu valgum deformity on the left with slight genu varum on the right. From the radiographic appearances it was assumed (rather naively as it transpired) that the left lateral femoral condyle, epiphysial plate and part of the metaphysis were destroyed and that similar damage had been inflicted upon the right medial tibial condyle. The metaphysial spurs were interpreted as indicating the point at which longitudinal bone growth had ceased.

It was thought that this situation represented the ideal indication for an attempt at epiphysial transplantation, and such was our confidence that we began the operation by removing the upper end of the left fibula with the intention of transplanting it into the bony lower lateral femoral diaphysis which we expected to find. When the knee joint was opened,

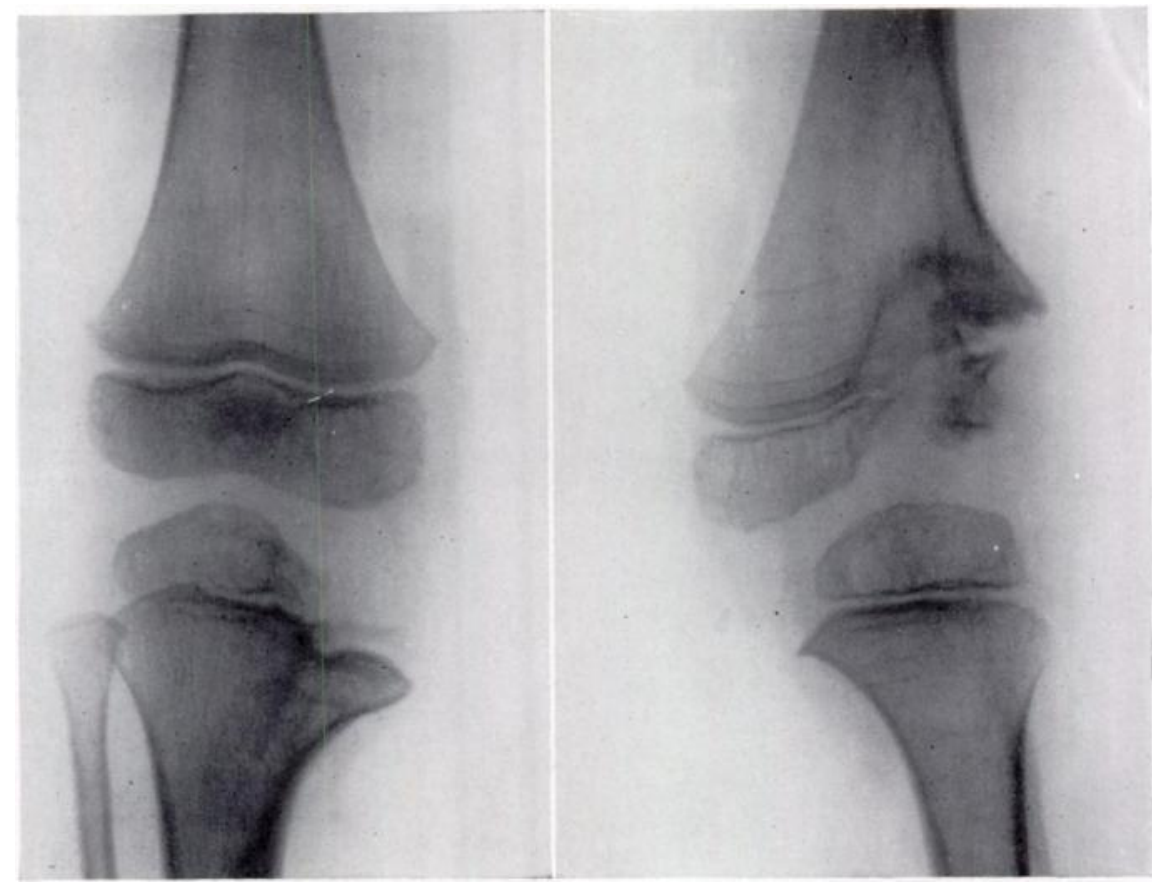

Fig. 3

Case 1-Appearances three years after operation. Note the fibular graft in the left femur and evidence of recalcification in the region of the right medial tibial condyle.

however, some consternation was felt when an apparently undamaged lateral femoral condyle was exposed lying within a joint which, apart from some adhesions, appeared to be normal. Fearing nevertheless that the hidden epiphysial plate might have been destroyed the graft was introduced as originally intended.

Figure 3 illustrates the radiological state at the present time, four and a half years after the infection occurred and two and a half years since the operation. There is no shortening, one and a half inches of genu valgum, insignificant lateral instability and 110 degrees of flexion from full extension of both knees.

Comment-Three months after the operation the child was admitted for reassessment, or rather for the assessment that should have been made earlier. This examination revealed the following signs, the significance and reliability of which have been substantially confirmed in six other patients who are briefly described below. 
Clinical signs in relation to the radiological-1. The cartilaginous condyle could be seen and felt in its correct position with the knee flexed to 90 degrees (Case 4, Fig. 4).

2. Movements were surprisingly free, being from 180 to 70 degrees on the right and 180 to 90 degrees on the left (after operation). Case 4 (Figs. 5 and 6) illustrates this feature

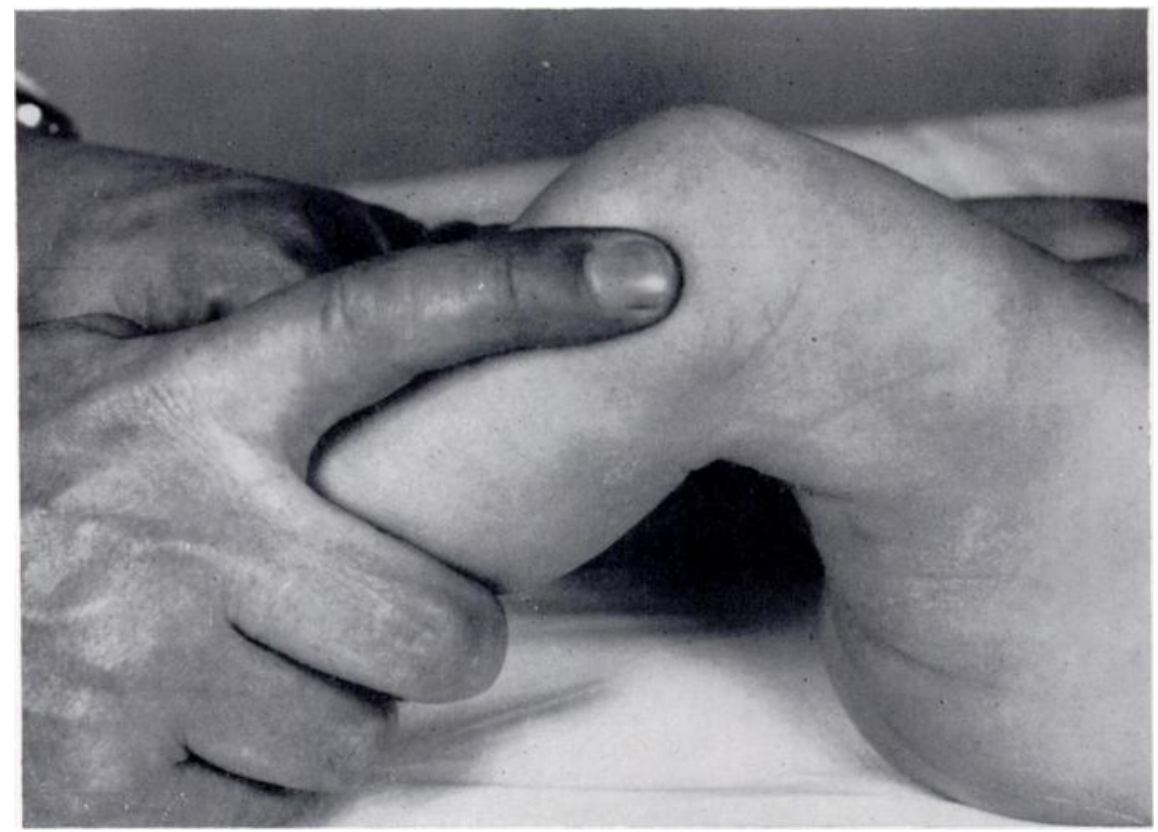

Fig. 4

Palpating the lateral femoral condyle. The radiograph of this patient (Case 4) is shown in Figure 16.

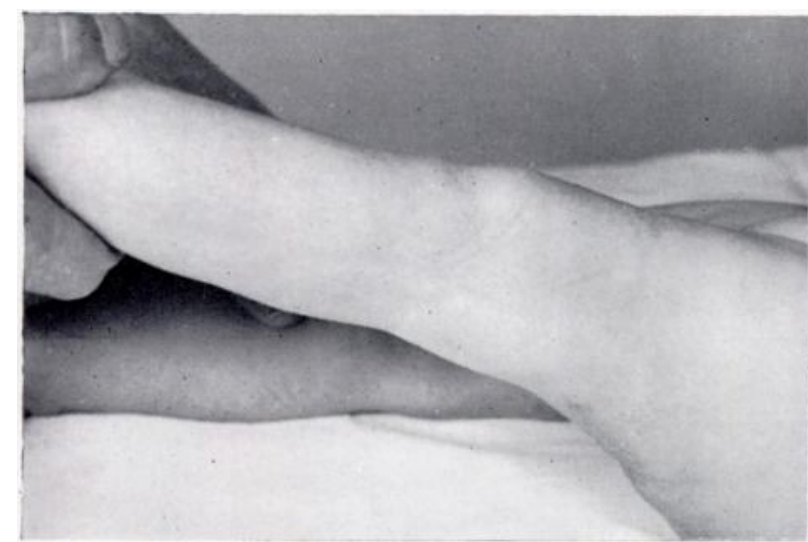

Fig. 5

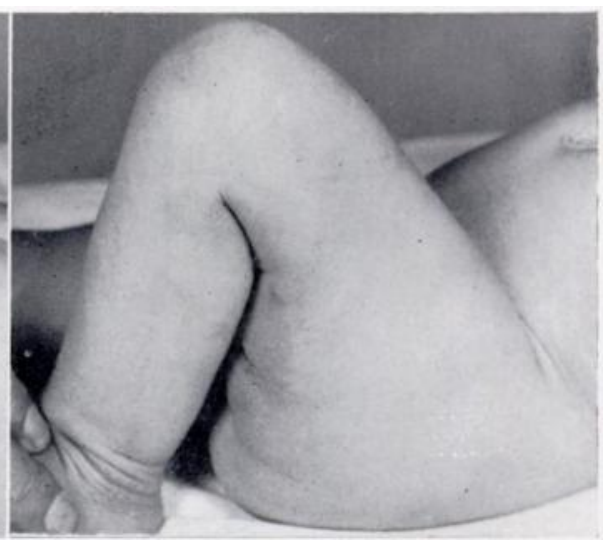

FIG. 6

Figure 5-Shows that full extension is retained. Figure 6-Showing the range of flexion. (Case 4; compare Figure 16.)

even more strikingly. It is inconceivable that such freedom could follow destruction by pus of so large an area of bone within a joint.

3. There was only slight knock-knee deformity (malleolar separation one and a half inches) after two years of seeming loss of the lateral half of the femoral epiphysis. If part of the

VOL. 42 B, NO. 4, NOVEMBER 1960 


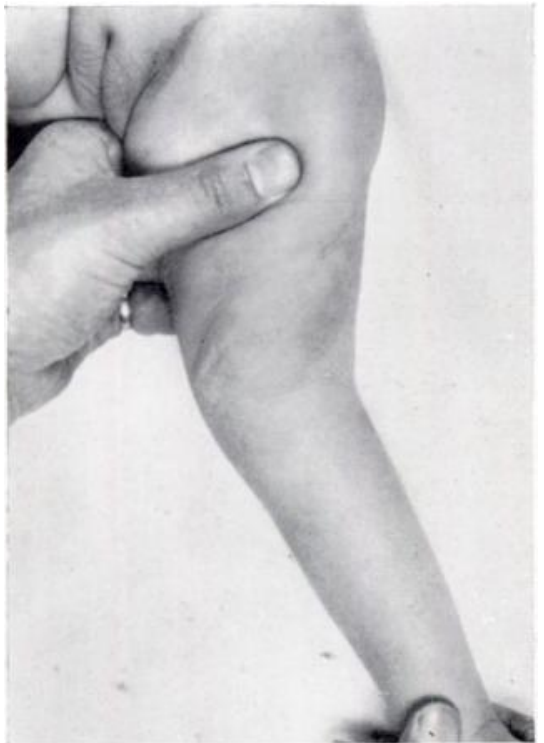

FiG. 7

The knee is being abducted in extension. Relative stability is preserved. epiphysis had in fact been destroyed the deformity would have been much greater. At the present time (over four years since the onset) the deformity remains the same.

4. There was (and still is) no shortening. This might have been due to bilateral involvement but, even so, shortening has been a problem in only one patient (Case 3).

5. The knee in extension was much more stable than might have been expected if half of the epiphysis had indeed been lost (Case 4, Fig. 7).

Radiological signs-1. The metaphysial spurs are potentially misleading but are in fact good evidence that the epiphysial cartilage is not irreparably destroyed. They are present on both sides in this patient and are a constant feature in the radiographs of all the patients and are illustrated in Figures 1, 2, 10, 11, 13, $15,16$.

2. In a high quality radiograph of low penetration the outline of the cartilaginous condyle may be seen.

3. Arthrographs (Figs. 8 and 9) of the right knee demonstrated the survival of the epiphysis beyond any doubt. There were, however, such obvious signs of this on clinical examination that this was merely a refinement.

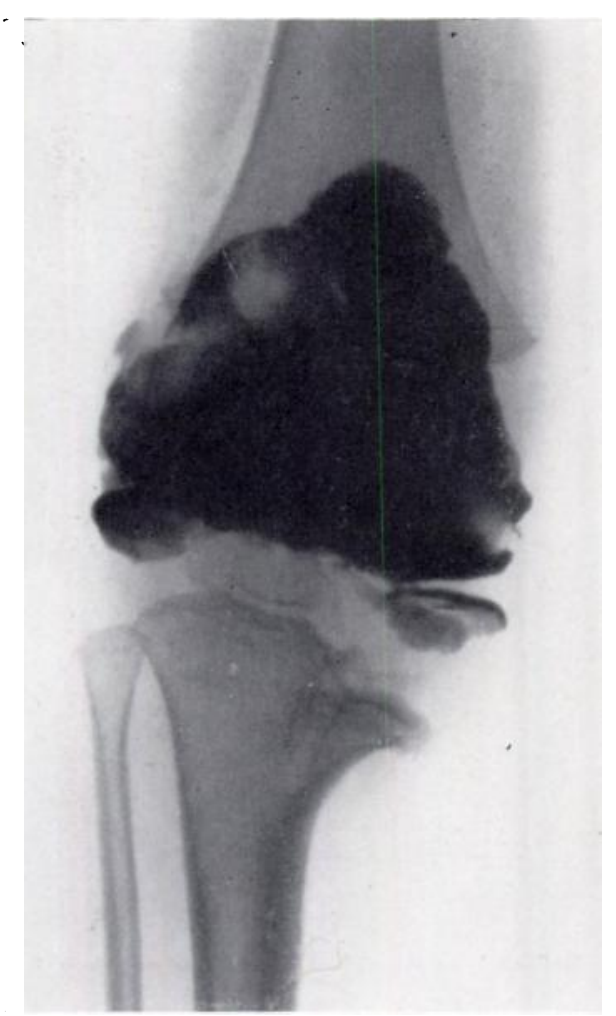

FIG. 8

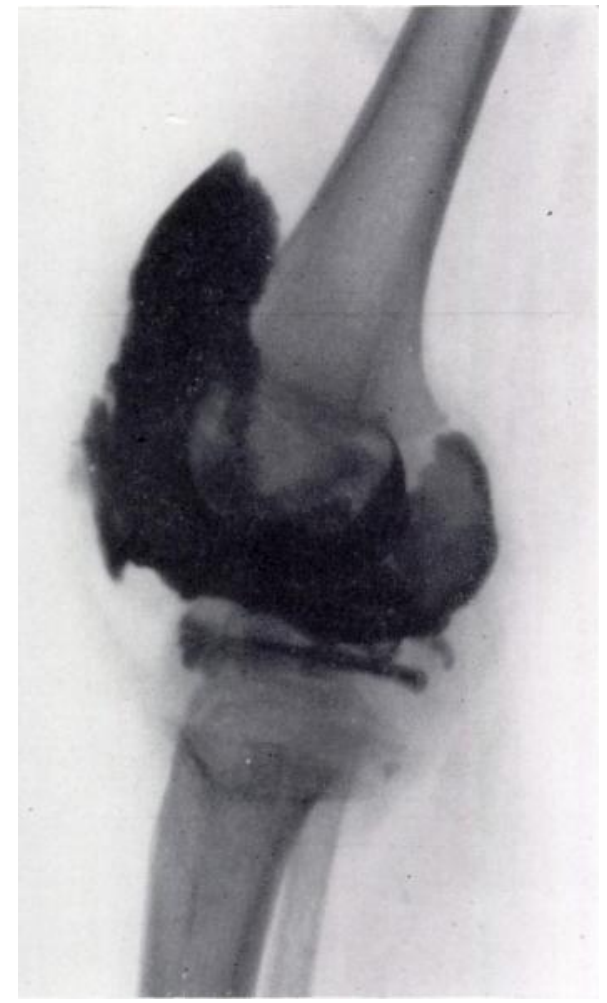

FIG. 9

Case 1-Arthrographs of the right knee showing the outline of the cartilaginous epiphysis of the medial tibial condyle. 


\section{OTHER CASES}

Short case histories of a further six patients who have had suppurative arthritis of the knee will now be presented and thereafter some salient features will be mentioned.

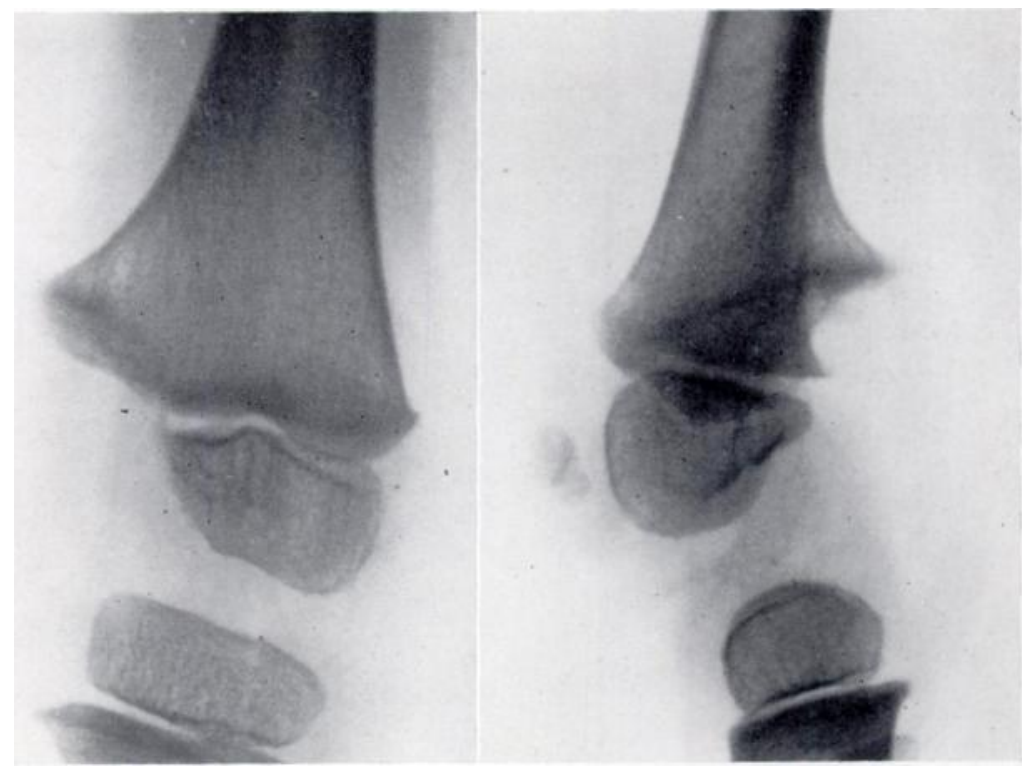

FIG. 10

Fig. 11

Case 2-Radiographs taken at thirteen months. Note the apparent loss of the medial third of the femoral epiphysis, the sloping epiphysial plate and the metaphysial spur (Compare Figure 1.) In the lateral radiograph (Fig. 11) the metaphysial spur is well shown. (Compare Figure 2.)

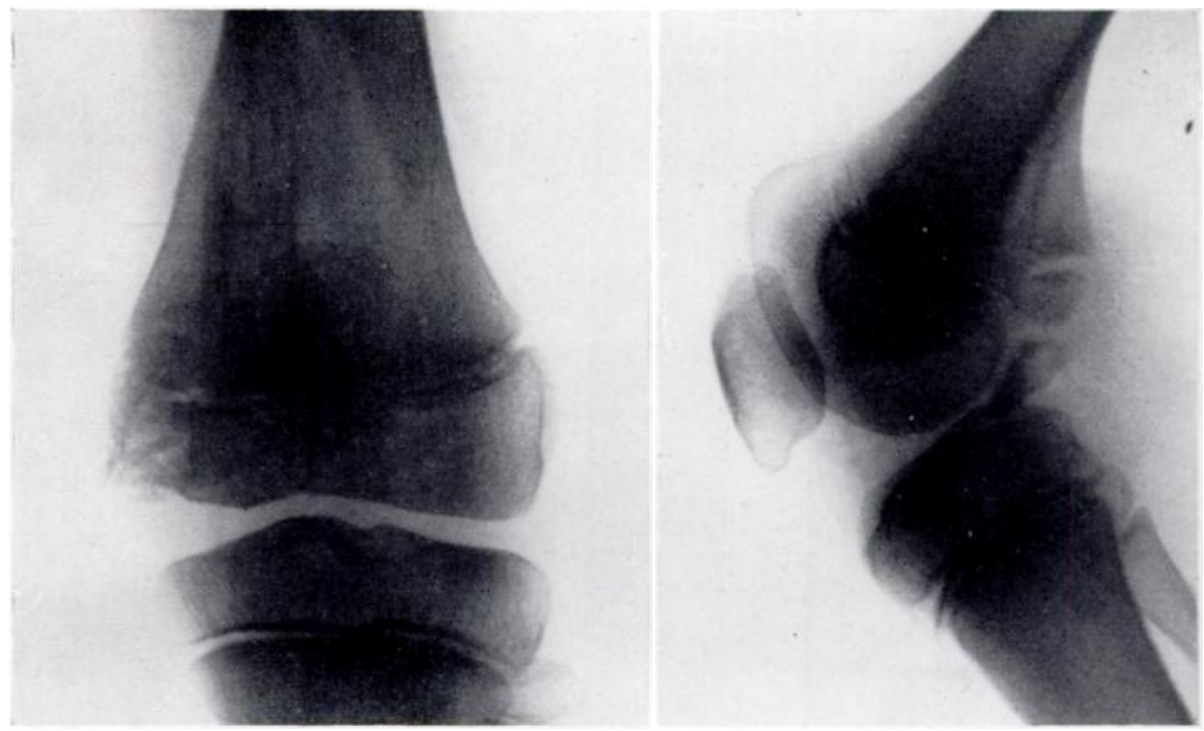

FiG. 12

Case 2-The appearances at thirteen years old. The degree to which the condyle now approaches normal can be seen.

Case 2-A girl, aged thirteen months, was first seen one year after a staphylococcal suppurative arthritis of the knee at three weeks. She had been treated by aspiration, penicillin replacement and systemic penicillin. Radiographs taken at the time of her first attendance are shown in Figures 10 and 11. On examination she had mild genu varum and shortening of half an inch. There was full

VOL. 42 B, NO. 4, NOVEMBER 1960 
knee flexion from a fixed flexion deformity of 15 degrees. She had worn a bow-leg splint for six months but has had no treatment since.

Radiographs twelve years later (Fig. 12) show the remarkable extent to which the lower end of the femur survived the infection. No less remarkable is her clinical state, for from the fully extended position she has full flexion less 10 degrees, the knee is stable in extension, the limb is less than an inch short, and genu varum is only just enough to allow a half-inch gap between the extended knees.

Case 3-An infant boy suffered suppurative arthritis, the pus from which yielded staphylococcus aureus. Two years later the radiograph (Fig. 13) resembled those of Cases 1, 2 and 4 . At that time there was no shortening, movements were full and the knee was stable. There was, however, genu varum of such severity that osteotomy was considered. Nevertheless the deformity gradually improved without treatment and was found to be fully corrected four years later. At the same time shortening was first noticed: this progressed, so that a discrepancy of two inches existed after a further five years at the age of eleven. The opposite femoral epiphyses were accordingly stapled and some improvement was noted six months later. The boy is now twelve and his radiograph is reproduced (Fig. 14). He plays all games, has no varus deformity and almost full movement. The knee remains stable.

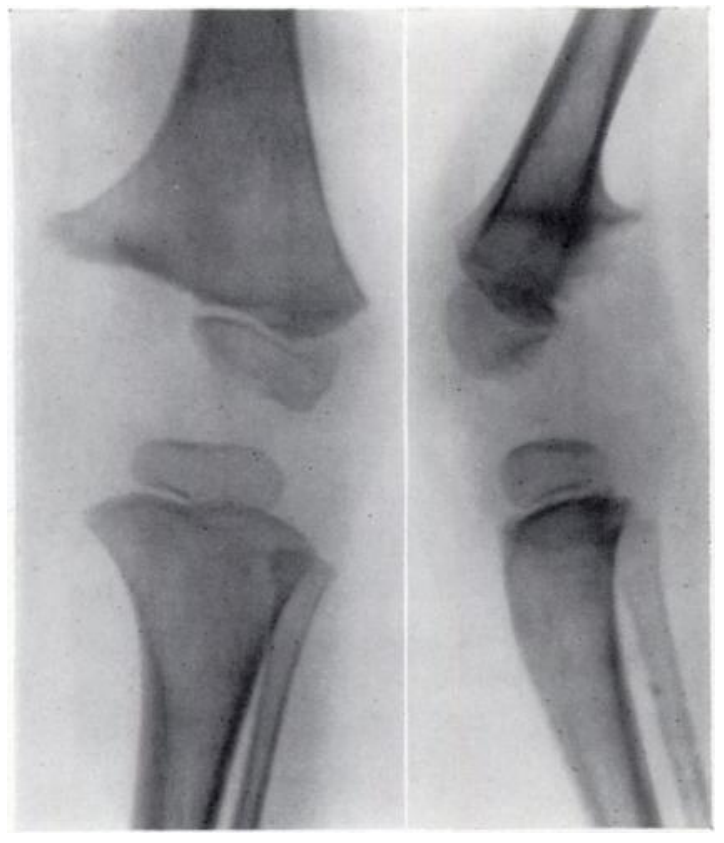

Fig. 13

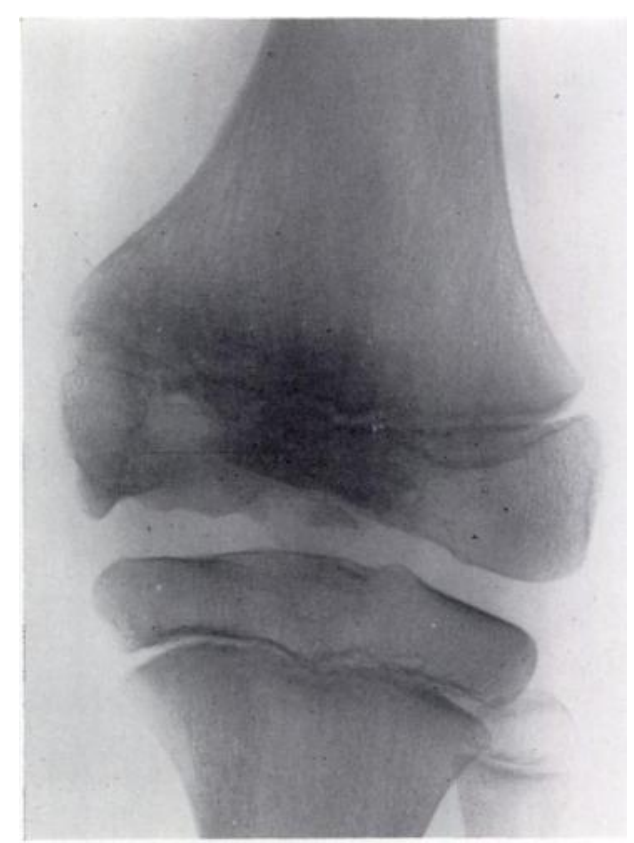

Fig. 14

Case 3-Suppurative arthritis of knee. Figure 13-Two years after the onset. (Compare Figures 1, 2, 10, 11.) Figure 14-At twelve years old there has been improvement with growth but the final result is less good than in Case 2 (Fig. 12).

Case 4-A girl, aged five weeks, was admitted with swelling of the knee of one week's duration. Aspirated pus yielded staphylococcus aureus. Radiographs (Fig. 15) already showed marked decalcification, translucency of half the condyle and early metaphysial " spur" formation. Penicillin was injected into the joint and systemically, together with Novobiosin and Nystatin by oral tube. The baby was gravely ill with staphylococcal septicaemia, and after ten days tetracycline was substituted for the other antibiotics and the knee was splinted in extension. This treatment was continued for ten weeks and thereafter a polythene splint was substituted.

Eighteen months after the onset there was full movement at the knee (Figs. 4 and 5), the condyle was palpable (Fig. 3) and the knee was relatively stable (Fig. 6). There was no shortening, genu valgum allowed two inches of malleolar separation and she could stand unaided. Figure 16 shows a radiograph taken at this time.

Case 5-A boy, aged two weeks, was admitted with a staphylococcal septicaemia and osteomyelitis of the left femur with symptoms for one day. Radiographs showed an area of translucence in the lower lateral femoral epiphysis which soon spread to include the metaphysis and the lateral half of 


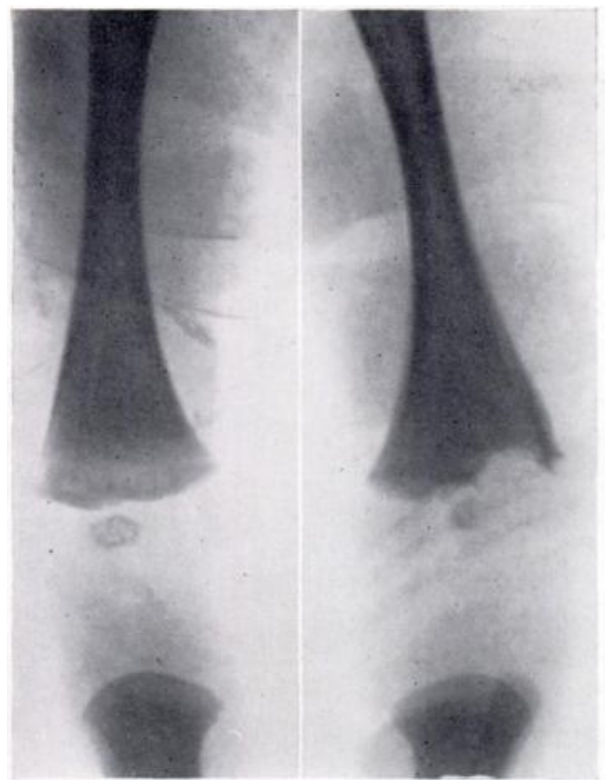

FIG. 15

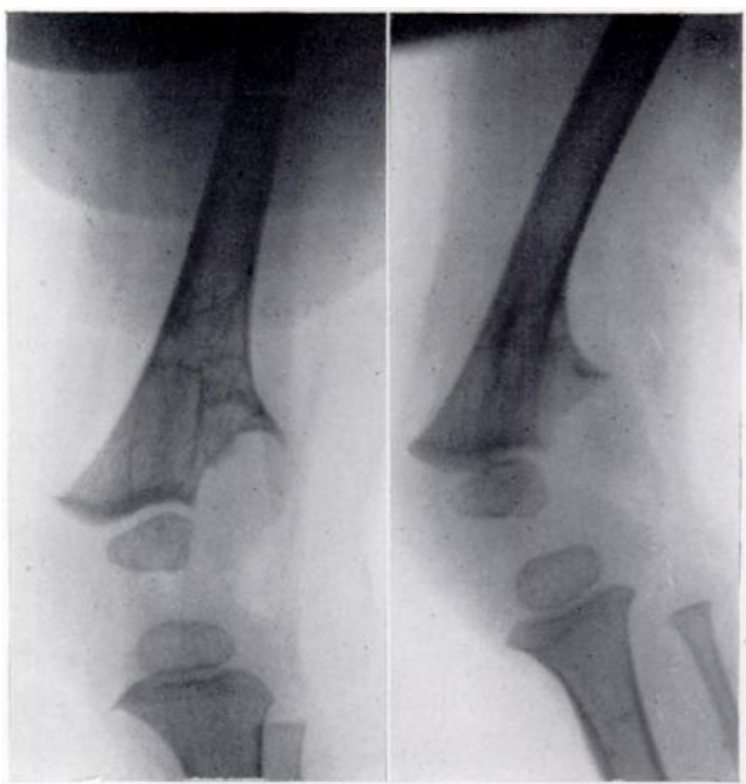

Fig. 16

Case 4. Figure 15-Radiograph taken seven days after the onset of the infection showing the speed with which decalcification occurs. Figure 16-One year later. The metaphysial spur, sloping epiphysial plate and loss of part of the normally opaque epiphysis are well shown. (Compare Figures 1, 2, 10 and 11.) This was the radiographic picture when the clinical photographs (Figs. 4 to 6) were taken.

the epiphysis. Penicillin and tetracycline were prescribed. A day later an abscess was drained on the lateral side of the thigh and a plaster was applied. Sequestrectomy and curettage of the femur were subsequently performed twice, a further abscess was drained and the child was again admitted for treatment with antibiotics before final healing occurred about three years after the onset.

Seven and a half years later the affected leg was two inches short and genu valgum allowed two and a half inches of malleolar separation. Nevertheless the knee was fully stable and lacked only 10 degrees of flexion. Radiographs showed the lower femoral diaphysis to have remodelled normally: the epiphysial plate was still translucent and there was some bone forming in the lateral femoral epiphysis which was palpable. Further improvement is therefore probable.

Case 6-A boy, aged three weeks, was admitted with a staphylococcal infection of the femur closely resembling that found in Case 5. An abscess required incision, but healing was by primary intention. Systemic treatment was by aureomycin and the organism was again a staphylococcus.

Five years later radiographs showed the typical metaphysial spurs and a translucency in the area normally occupied by the lateral half of the femoral epiphysis. In spite of genu valgum which allowed five inches of malleolar separation the knee was stable and movement full. Shortening was less than half an inch.

Case 7-A boy aged five weeks was admitted with suppurative arthritis of the knee caused by staphylococcus aureus. He was treated by splints and aureomycin for six weeks. Radiographic changes of the type already described affected the lateral half of the distal end of the femur. Full movement, normal longitudinal growth and relative stability were maintained, but in this patient the valgus deformity was of such a degree that supracondylar osteotomy was performed when the child was two years old.

\section{DISCUSSION ON AFFECTION OF THE KNEE}

In all seven patients staphylococcus aureus was the organism responsible, and in all frank pus was at one time or another obtained from the region of the knee joint. The demonstrable after-effects were always confined to one half of the femoral or tibial metaphysis and epiphysis, and it must be assumed that the vascular supply of the area dictates this.

Cases 2 and 3 are important because they show the recovery that can occur with time. The child in Case 2 continued to improve until skeletal maturity; so it is possible that a patient 
reported by Hall (1954) at eight years old with stability, no genu varum, 70 degrees of movement and two inches of shortening after "loss" at the medial femoral condyle will do likewise. Case 3 resembles Hall's case very closely and the patient continues to improve.

These patients support the submission that neonatal suppurative arthritis of the knees showing the clinical and radiological features already described have a relatively good prognosis in terms of mobility and stability. Impairment of longitudinal growth or the development of a valgus deformity may occasionally require surgical correction (Cases 3 and 7). We should certainly be on guard against over-enthusiastic acceptance of apparently successful transplantation of growing epiphysial plates in such cases as these.

\section{PYOGENIC ARTHRITIS OF THE HIP}

Failure to distinguish between decalcification and destruction in pyogenic arthritis of the knee results in no more than unnecessary operation or inaccurate prognosis. A similar mistake in the hip, however, may have more serious consequences. It may mislead the surgeon into advising against treatment in the belief that he is dealing with an irreparable dislocation from destruction of the proximal end of the femur when, in fact, enough decalcified bone remains for repair. I do not infer that destruction never takes place, but merely suggest that the apparent absence of bone radiologically does not necessarily imply bone destruction.

The surviving cartilaginous femoral head is sometimes dislocated during the acute phase of the infection (Case 13, Fig. 27), so that a situation develops which is incapable of spontaneous cure whatever the possibilities of remineralisation. These are the patients for whom treatment is likely to be of benefit. Time may be short, however, because the cartilaginous femoral head does not seem to grow in its ectopic position. This suggestion is supported by findings in two patients operated upon in adult life. These patients had rudimentary cartilaginous femoral heads and necks which were removed in the course of fusion operations. It is perhaps not unreasonable to ask whether these rudiments found in the adult and similar in size to the normal structures in infancy would not have developed more normally had they been replaced in the acetabulum at an early age.

Four of the cases to be presented (Cases 9, 10,12 and 13) illustrate the advantages of early manipulation or exploration of a hip that is dislocated or "destroyed." In another patient (Case 8) the damage inflicted was found to be irreparable when the hip was explored. No harm came of this and we were satisfied that no opportunity of helping the child had been neglected. This case is not reported in detail below.

\section{CASE REPORTS}

Case 9-A girl, aged sixteen days, was admitted with high fever, a swollen thigh and umbilical sepsis. Aspiration of the hip on the same day produced 10 cubic centimetres of pus from which haemolytic streptococci sensitive to penicillin were cultured: the same type of streptococcus was grown from the umbilicus. Penicillin was given on admission and on the next day an abscess which lay in front of the joint capsule was drained. There was no pus in the femoral neck. The wound was sutured and a plaster was applied in abduction. The baby made a rapid recovery and was discharged home after receiving penicillin for six weeks. Pathological dislocation of the hip was then noted (in spite of early abduction) and a divaricator was ordered. This was unsatisfactory; so the plaster was reapplied but was soon removed because the hip was considered to be damaged beyond repair (Fig. 17). Figure 18 shows the appearance of the hip at fifteen months when the child began walking. This was interpreted as showing destruction of the femoral head and the lower half of the neck.

Two years later, when she was three years and three months old, the leg was an inch short and the hip unstable. Arthrography confirmed the dislocation but it suggested that the femoral neck and head were not totally absent (Fig. 19).

At exploration the femoral head was grossly misshapen and resembled a mushroom, but was nevertheless large enough to permit reconstruction of the hip. There was anteversion of about 90 degrees in addition to excessive valgus of the femoral neck. The acetabulum was a shallow saucer filled with bone mixed with cartilage. It was not possible to bring the femoral head down to this level; so a socket was gouged out of the ilium immediately above the true acetabulum. The reconstructed 
hip was stable in abduction and medial rotation and was immobilised in plaster in that position. Intertrochanteric adduction and lateral rotation osteotomy was carried out four months later and the plaster was finally removed after a further six weeks.

A year later she was able to walk without pain and (with the shoe raised half an inch) without a conspicuous limp. She had a stable hip joint with a negative Trendelenburg sign and less than an

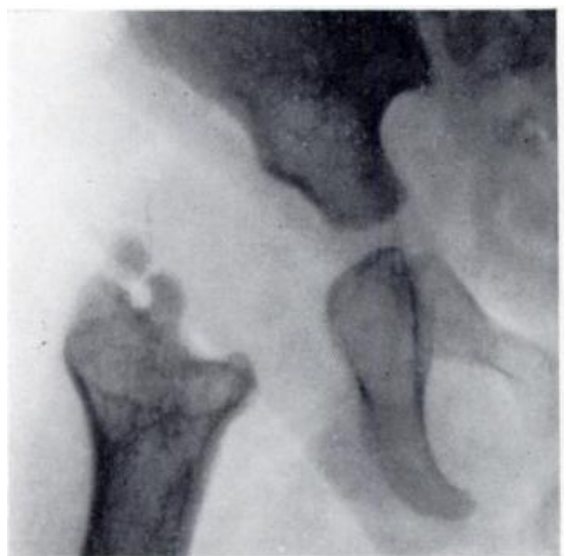

FIG. 17

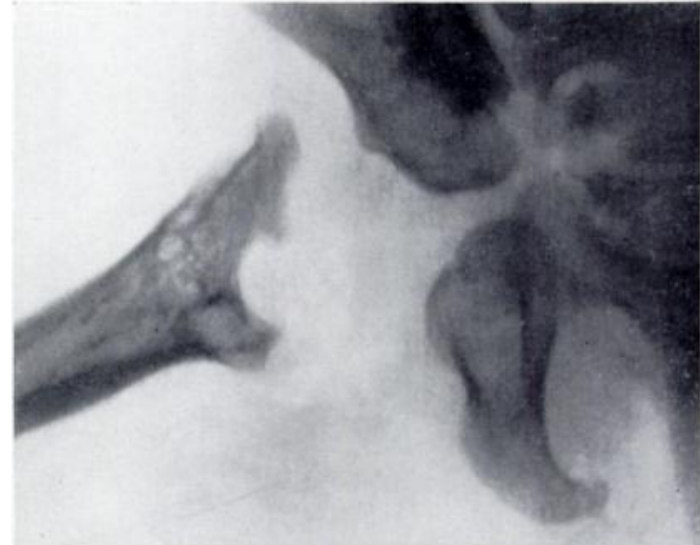

FIG. 18

Case 9. Figure 17-The hip three months after the infection began and before walking. Figure 18-At two years old after walking. The hip is dislocated and there is apparent loss of half the femoral neck, the epiphysial plate and the capital epiphysis.

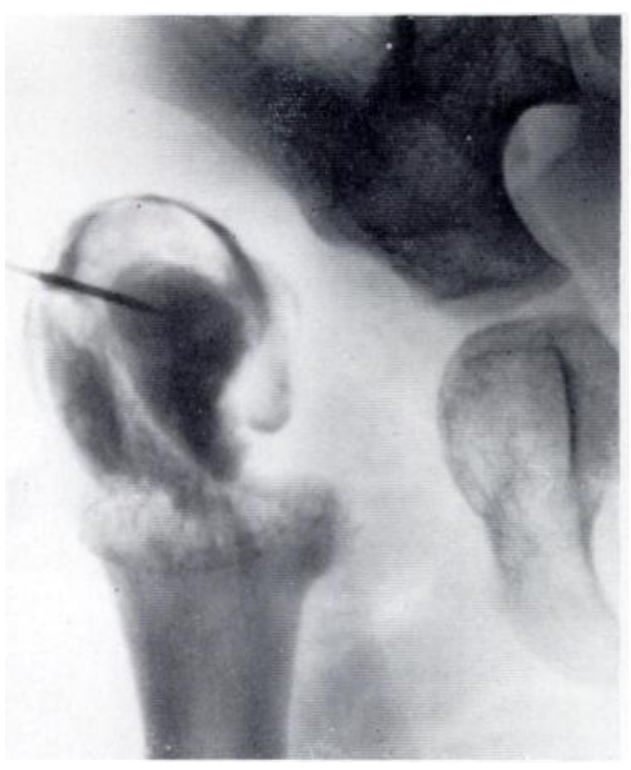

FiG. 19

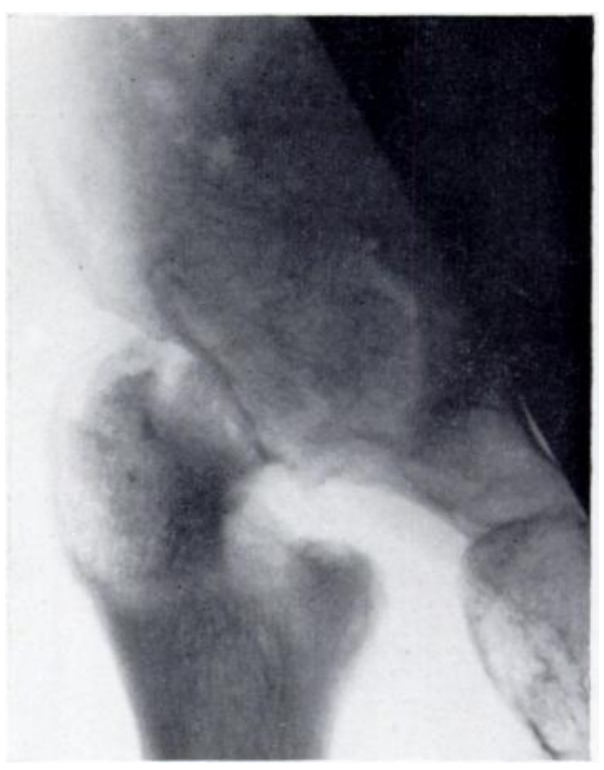

FIG. 20

Case 9. Figure 19-Arthrograph made at the same time as Figure 18. The surviving cartilaginous epiphysis is shown. The needle has entered the femoral head and the contrast so produced suggests that the epiphysial plate has survived as a translucent band distal to the opaque part of the head. Figure 20-One year after operation the now ossified head can be seen within the new acetabulum and the lower edge of a translucent line in the position of the epiphysial plate is visible.

inch of shortening well compensated by some residual fixed abduction. She had 20 degrees of fixed flexion deformity and 20 degrees of flexion therefrom.

Comment-Although this cannot be considered a wholly satisfactory outcome it compares favourably with the alternatives of progressive shortening and instability. Furthermore, there now exists a situation which will favour successful arthrodesis should this become necessary in the future (Fig. 20).

VOL. 42 B, NO. 4, NOVFMBER 1960 
Case 10-A boy, aged thirteen months, presented one year after the onset of arthritis which had been treated by antibiotics for one month at three weeks of age. An earlier radiograph (Fig. 21) at the time that the infection was subdued shows that the hip was dislocated and suggests that serious damage

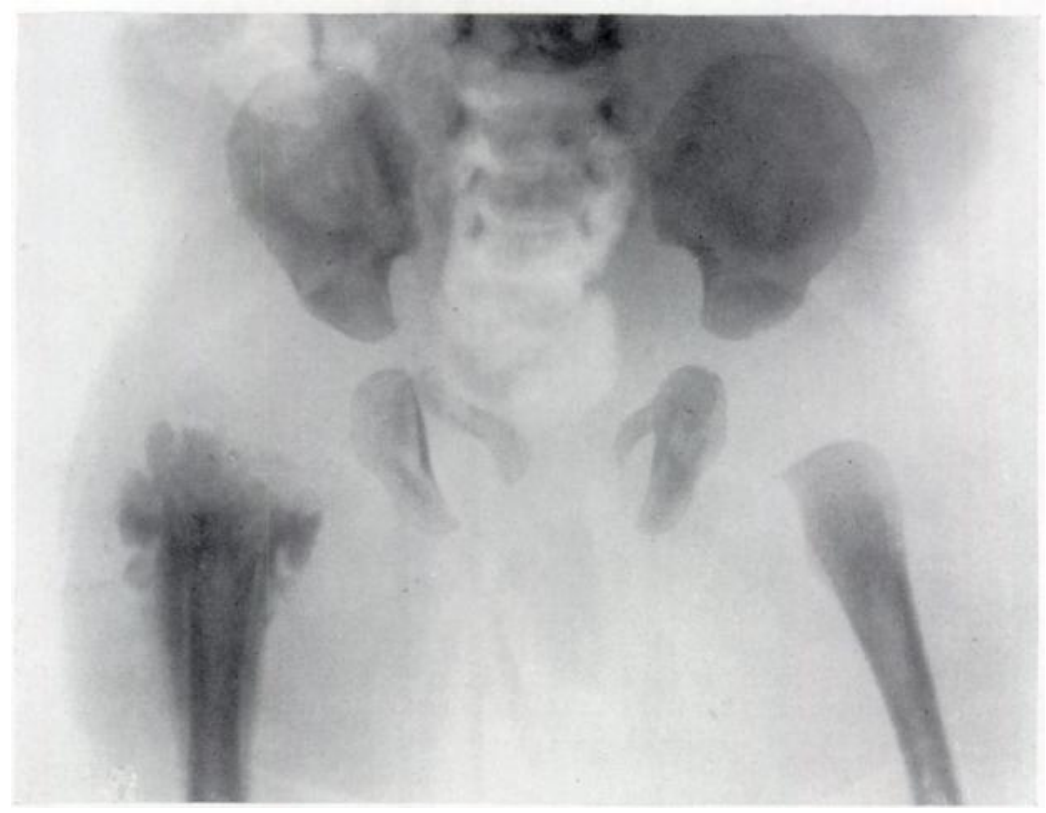

Fig. 21

Case 10-Radiograph taken soon after the onset of the infection showing that the hip is dislocated and serious damage seems to have been inflicted upon the upper end of the femur.

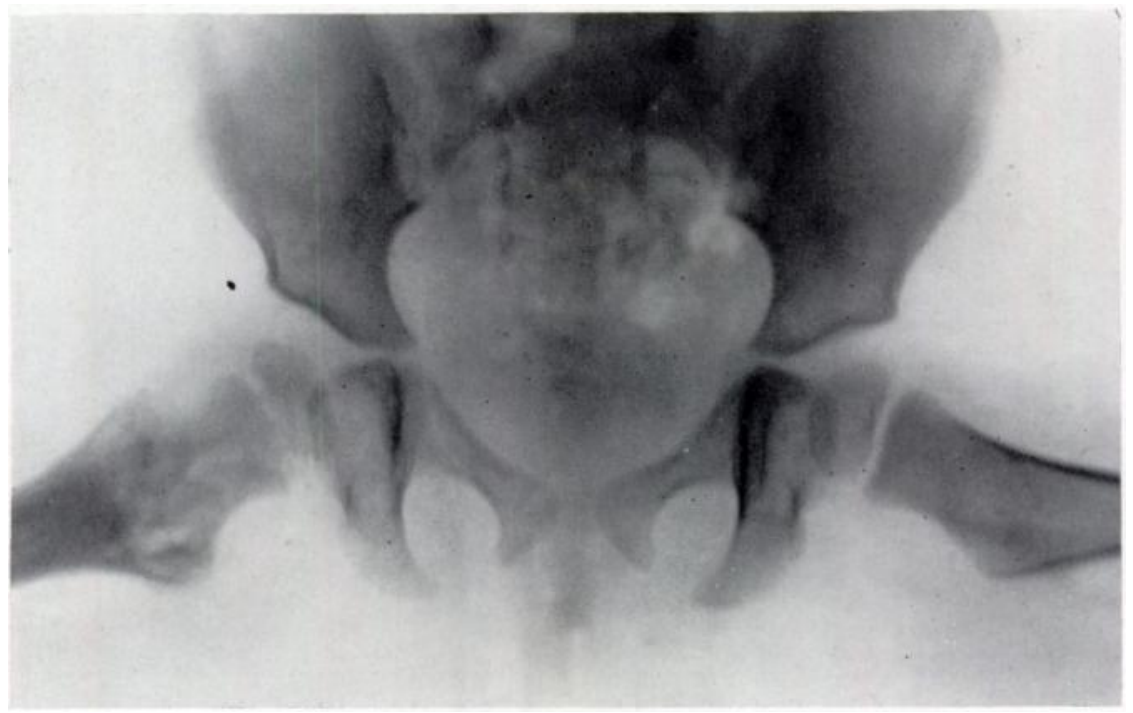

FIG. 22

Case 10-Condition one year later showing the extent to which the hip has improved radiologically.

had been inflicted upon the upper end of the femur. The dislocation was reduced by closed manipulation and one year later the promising situation shown in Figure 22 had developed.

Comment-This case demonstrates the success of closed manipulation as late as one year after pathological dislocation had occurred. 
Case 11-A girl, aged ten days, was seen three days after the onset and two days after streptococcal pus had been aspirated from the hip joint. The radiograph showed the upper end of the femur to be lying too high and too far laterally. A plaster was applied in 90 degrees of abduction and retained for three weeks during which the acute infection was controlled, though by now typical changes of osteomyelitis were visible above the acetabulum. She was seen at the Hospital for Sick Children when one year old with the femoral head still not visible on the affected side though well developed on the other. The ossific nucleus appeared at fourteen months and now (three years from the onset) closely resembles the normal. Shortening is trivial, the hip is stable, and movements are limited by one-third in abduction and rotation only.

Comment-This case illustrates the importance of early treatment in abduction and emphasises that absence of an ossific nucleus after it should have appeared does not mean that it is necessarily destroyed. Eyre-Brook (1960) drew attention to the importance of rest in abduction which, with aspiration and antibiotics, enabled him to obtain four good results in ten patients without the need for manipulation or operation later.

Case 12-A girl, aged two and a half years, was admitted to the Hospital for Sick Children having suffered acute arthritis due to staphylococcus aureus in infancy. Repeated aspiration yielded pus for one week after the beginning of antibiotic therapy. Three months later a sequestrum was removed

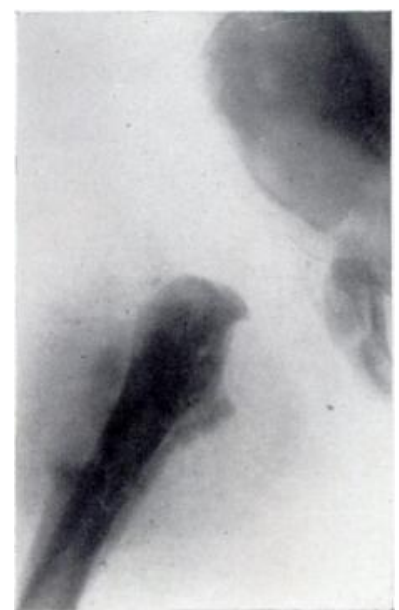

FIG. 23

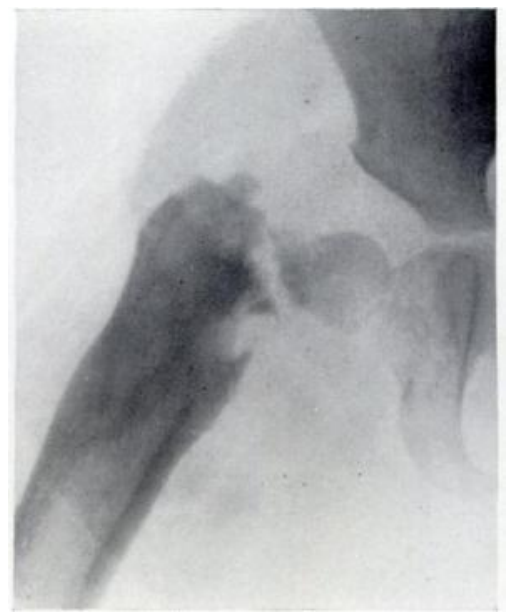

FIG. 24

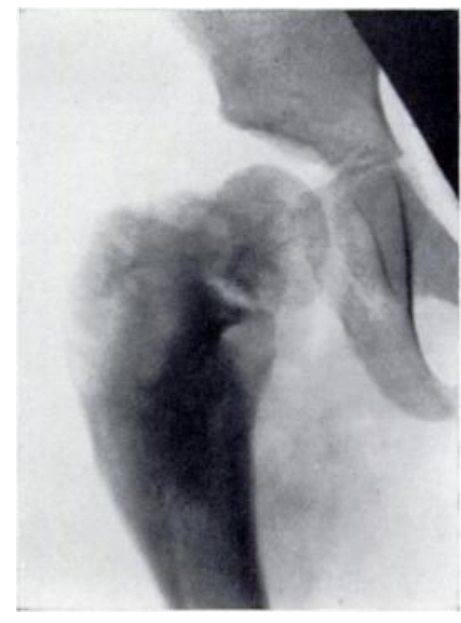

FIG. 25

Case 12-Radiograph one month after the onset of the infection. Figure 24-Appearance at the time of the operation. There is an apparent pseudarthrosis of the femoral neck but the capital epiphysis remains in the acetabulum. Figure 25-Appearance two years after exploration and abduction osteotomy. There is bony union at the femoral neck.

from the neck of the femur and this was followed by the drainage of pus for six weeks before final healing occurred. A radiograph (Fig. 23) shows the state of the upper end of the femur about a month after the infection was diagnosed.

On admission to the Hospital for Sick Children the radiographic appearances were as shown in Figure 24, when exploration was decided upon. At operation the femoral neck was found to be in fibrous continuity at the point of apparent pseudarthrosis; so an intertrochanteric abduction osteotomy was performed with medial displacement of the lower fragment. One year later sound union has occurred (Fig. 25) and the hip is stable. There is flexion through 80 degrees, full adduction and rotation, but no abduction from the neutral position. The leg is one inch shorter than its fellow.

Comment-Although the translucent area might well have recalcified if it had been left alone operation established again that translucency after osteomyelitis does not necessarily mean that bony tissue is lost, and the osteotomy both encouraged rapid remineralisation and reduced the varus deformity.

Case 13-An infant boy suffered an acute staphylococcal infection of the upper end of the femur which responded rapidly to antibiotics alone but later caused the hip to dislocate (Fig. 26). Closed manipulation was unsuccessful. At nine months he was admitted to the Hospital for Sick Children 


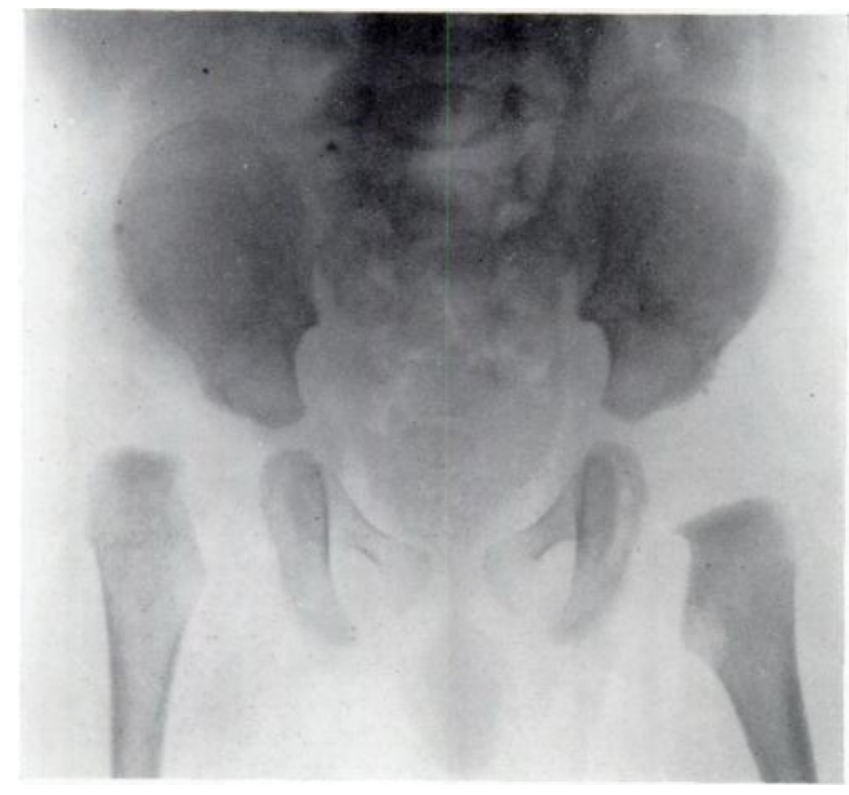

Fig. 26

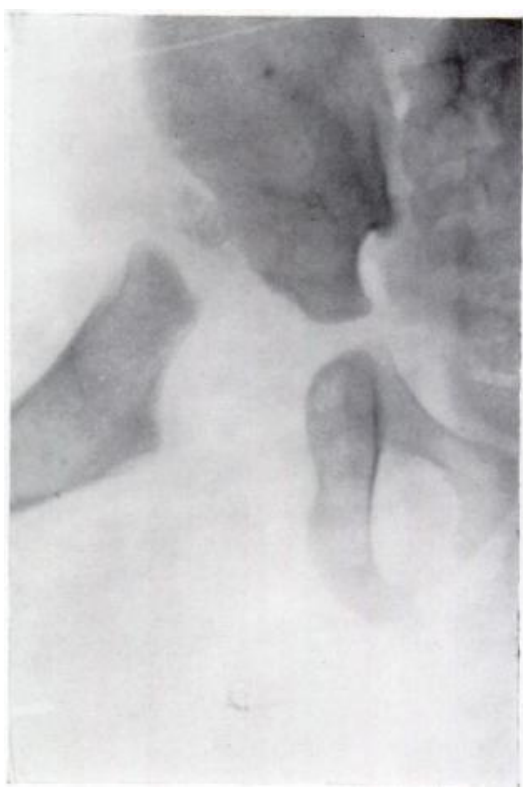

Fig. 27

Case 13. Figure 26-Radiograph showing the dislocated hip of a child aged ten weeks, six weeks after the onset of the infection. Figure 27-Condition at the time of operation at eight months of age. The capital epiphysis is ossified in the dislocated position.

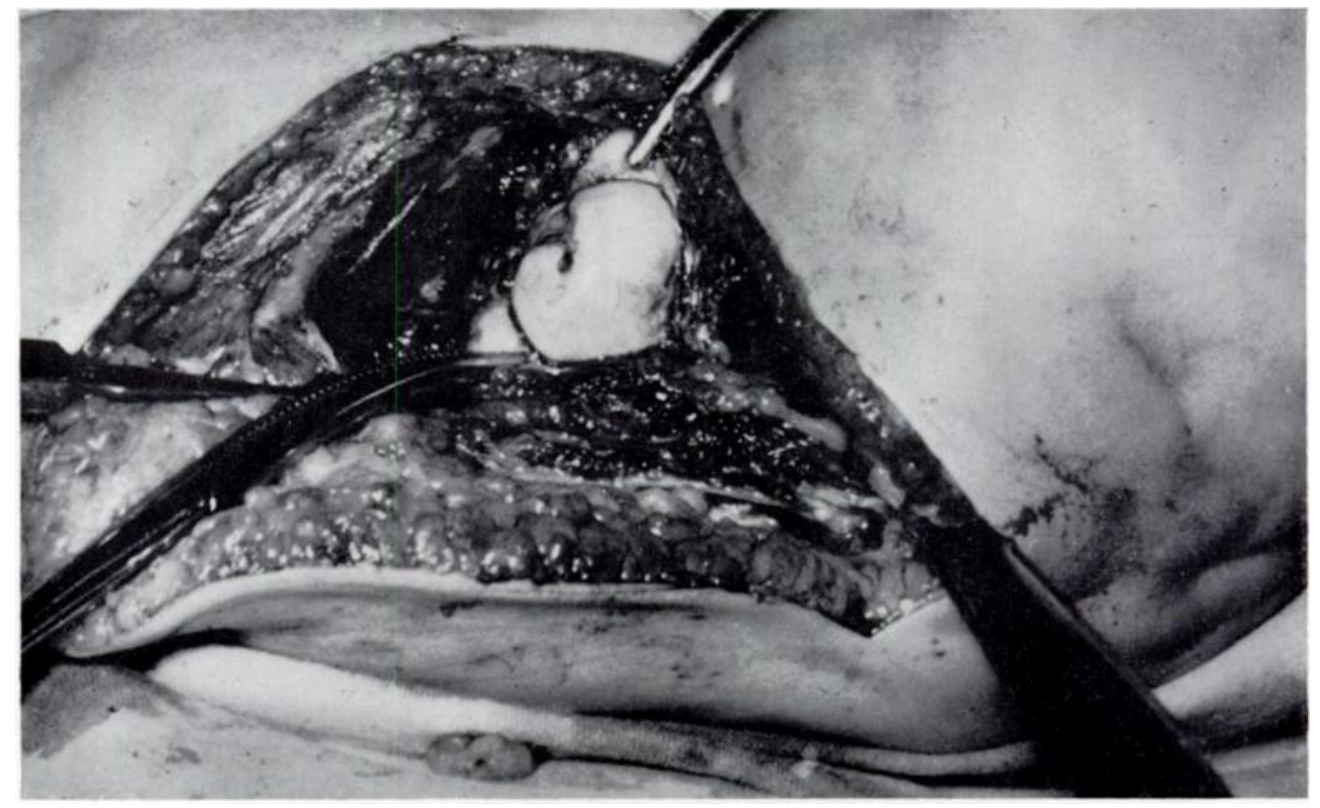

Fig. 28

Case 13-Photograph showing the head of the femur exposed at operation in the dislocated position. The forceps are gripping the capsule. The femoral head is relatively normal. 
and the hip was explored. The femoral head was found to be dislocated but of nearly normal contour and covered by apparently normal articular cartilage (Figs. 27 and 28). Reduction was achieved but the operation was followed by recrudescence of the infection which has spoilt what promised to be a successful result. Nevertheless the femoral head has remained in the acetabulum and there is ankylosis in good position without shortening.

Comment-Although this is disappointing the present state (Fig. 29) seems preferable to the alternative of shortening and instability with the prospect of a difficult arthrodesis to be undertaken in the future. It is probable, however, that a longer interval should have been allowed between the acute infection and operation, for no such complication followed exploration in Cases 9 and 12.

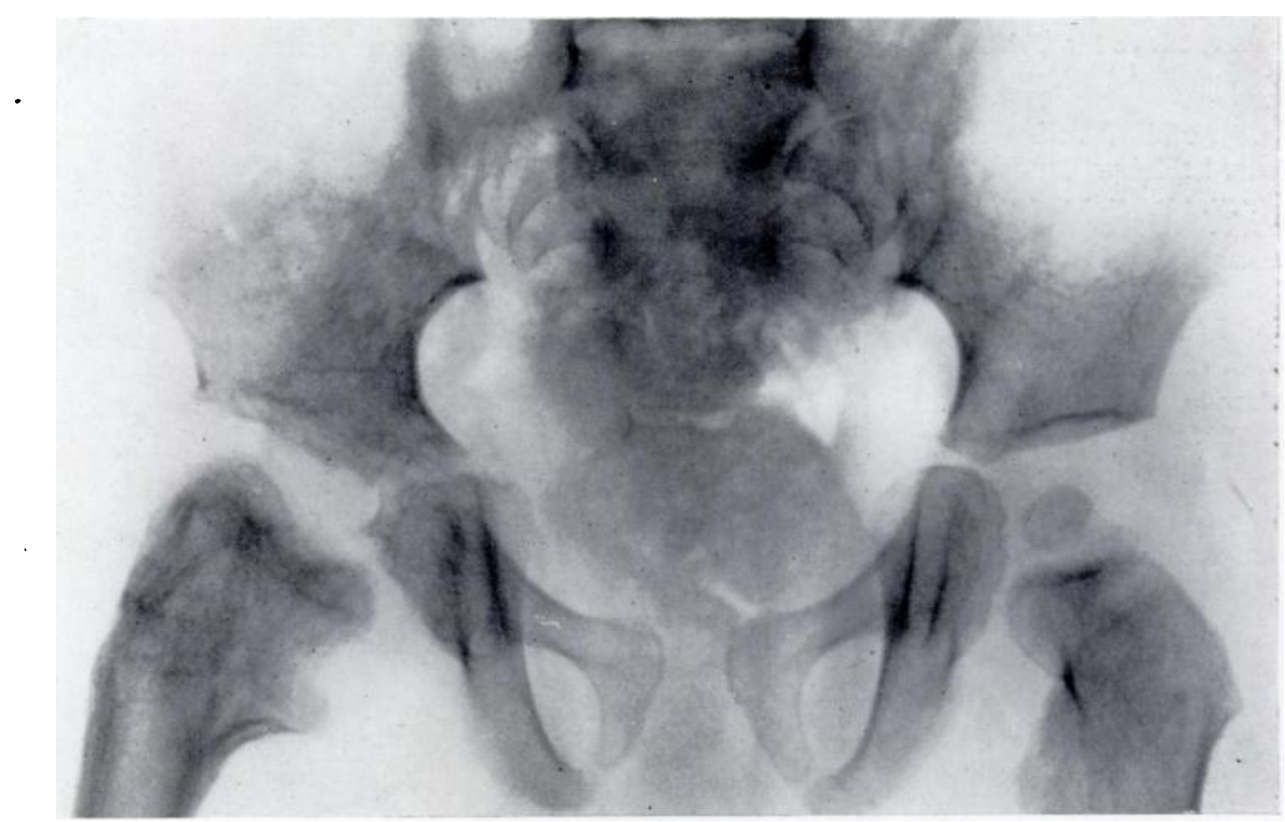

Fig. 29

Case 13-Condition one year after operation. Reduction and stability are maintained but recrudescence of the infection has further damaged the epiphysis and ankylosis is the result.

\section{DISCUSSION ON AFFECTION OF THE HIP}

It must be emphasised that neither dislocation nor destruction (apparent or real) of the hip joint necessarily contra-indicates an attempt to obtain a stable hip and reduce the shortening. At best the hip may be reduced by abduction alone or by manipulation; in less favourable cases open reduction into the original or a new acetabulum will decrease the ultimate disability. Osteotomy alone is clearly of benefit when the head survives in the acetabulum but part of the neck is lost. Eyre-Brook (1960) also illustrated its value when the head is lost but the neck remains in the acetabulum, and under certain other circumstances.

\section{SUMMARY}

1. Attention is drawn to the powers of resistance of the growing ends of bones in suppurative pyogenic arthritis of the knee and hip in infancy.

2. It is emphasised that a translucent zone in the radiograph does not necessarily mean that this part of the bone, epiphysial cartilage or plate is destroyed.

3. Diagnostic criteria are described to confirm that cartilage or decalcified bone has survived the infection in the knee joint.

4. The prognosis for the knee joint is discussed.

VOL. 42 B, NO. 4, NOVEMBER 1960 
5. The hip joint presents greater difficulties in diagnosis and greater issues are at stake. It is recommended therefore that the hip joint be manipulated or explored if the radiograph and the physical signs suggest that destruction of the joint has either caused dislocation or has so damaged it that dislocation is likely to occur in the future. In favourable cases stability may be restored to the hip. In the others a diagnosis of irreparable destruction is established and the surgeon is satisfied that an opportunity to help the patient has not been lost.

I am very grateful to the following for allowing me to report patients treated by them: $\mathrm{Mr} \mathrm{J}$. A. Cholmeley (Case 3), Mr D. R. Urquhart (Case 10) and Mr R. H. Young (Case 7). Mr E. A. Devenish (Case 11), Dr C. W. Kesson (Cases 1 and 9), Mr J. H. Meyer (Cases 5 and 6), Professor Alan Moncrieff (Case 4), Dr J. Sakula (Case 12) and Mr D. R. Urquhart (Case 13) generously made available to me clinical details of the early course and treatment of patients who subsequently came under my care. Professor $\mathrm{A}$. W. Wilkinson has kindly allowed me to follow the progress of the patient in Case 5, who is now under his care. It gives me pleasure to thank Mr Derek Martin for the clinical photographs and the reproductions of the radiographs.

\section{REFERENCES}

Banks, S. W., and Compere, E. L. (1941): Regeneration of Epiphyseal Cartilage. Annals of Surgery, 114, 1,076. BANKs, S. W., Krigsten, W., and Compere, E. L. (1940): Regeneration of Epiphysial Centers of Ossification. Journal of the American Medical Association, 114, 23.

Eyre-Brook, A. L. (1960): Septic Arthritis of the Hip and Osteomyelitis of the Upper End of the Femur in Infants. Journal of Bone and Joint Surgery, 42-B, 11.

HaAs, S. L. (1919): The Changes Produced in Growing Bones After Injury to the Epiphyseal Cartilage Plate. Journal of Orthopaedic Surgery, 1, 67,

HaLl, R.M. (1954): Regeneration of the Lower Femoral Epiphysis. Journal of Bone and Joint Surgery, 36-B, 116. Jones, Sir R., and Lovetr, R. W. (1923): Orthopedic Surgery, p. 277. New York: William Wood \& Company. 